\title{
Inflação e Crescimento no Longo Prazo
}

\section{José Luis Oreiro* Rodrigo Ayres Padilha*}

A inflação alta imputa prejuízos elevados ao crescimento, seja por criar custos financeiros elevados, variabilidade excessiva dos preços relativos e constituir-se de um processo instável para o cenário macroeconômico. É possível, por outro lado, que a inflação baixa venha a ajudar o crescimento, por apresentar-se como um mecanismo de acomodação dos desequilíbrios reais da economia, como os choques de oferta, a negociação de contratos de trabalho, etc.

$\mathrm{Na}$ medida em que o Brasil caminha para uma taxa de inflação de longo-prazo de 4\% ao ano, reabre-se o debate a respeito de qual seria a taxa ótima de inflação a ser perseguida pelo Banco Central no longo-prazo. Nesse contexto, deve-se observar que o valor atual da meta de inflação no Brasil (4,5\%) já é superior às expectativas de inflação de 2006 e do próximo ano. Alguns analistas propõem que a meta inflacionária deveria ser reduzida, seja porque há espaço para a queda ou dado que ela é superior às metas vigentes nos países desenvolvidos. Discutimos neste artigo se a meta atual é ou não apropriada para o Brasil.

Os problemas causados pela inflação são evidentes quando a taxa de inflação é alta (superior a dois dígitos, por exemplo), pois recursos escassos da economia são alocados de forma ineficiente para o mercado financeiro, ocorre uma variação excessiva nos preços relativos, impõe-se um imposto inflacionário que recai majoritariamente sobre os mais "pobres" e, normalmente, inicia-se um processo cumulativo que pode levar à hiperinflação. No entanto, os custos da inflação não são tão claros quando a inflação é baixa, ou seja, para uma taxa de inflação de um digito por ano. Com efeito, os estudos empíricos dos efeitos da inflação sobre o bem-estar não são conclusivos e, em alguns casos, apontam para a existência de uma relação positiva entre inflação e crescimento no longo prazo ${ }^{1}$.

Os potenciais benefícios de uma inflação baixa incluem a facilitação dos ajustamentos no mercado de trabalho, pois na medida em que os salários nominais são rígidos para baixo, a inflação permite que uma redução no salário real seja empreendida sem que haja

\footnotetext{
* Professor do Departamento de Economia da Universidade Federal do Paraná (UFPR). Endereço eletrônico: joreiro@ufpr.br

** Mestrando em Desenvolvimento Econômico pela Universidade Federal do Paraná (UFPR). Professor das Faculdades Santa Cruz de Curitiba. E-mail: rod_padilha@yahoo.com.br.

1 A relação ligeiramente positiva entre a inflação e o crescimento é encontrada, por exemplo, por Sarel (1996) e Ghosh e Phillips (1998).
} 
cortes no nível de emprego ${ }^{2}$. As evidências empíricas para os Estados Unidos coletadas por Groshen e Schweitzer (1997) sobre este efeito, apontam para a sua operação quando a inflação se encontra em até 5\%. Alguma inflação também é importante para manter a economia distante de um problema ainda maior, a deflação, cujos efeitos nocivos sobre o sistema econômico foram mais do que comprovados pela Grande Depressão de 1929. No entanto, a inflação baixa também tem seus custos, tais como a distorção nos impostos fixados nominalmente (como o imposto de renda), pois a carga tributária sobe mesmo quando os contribuintes não auferem aumentos reais nos seus rendimentos ${ }^{3}$; possibilidade da criação de alguns mecanismos de indexação, aumentado os efeitos da inércia inflacionária, etc.

O balanço entre custos e benefícios não é fácil de ser resolvido empiricamente, uma forma de analisar o problema é determinar a relação entre a inflação e o crescimento no longo prazo. O efeito negativo da inflação aparece normalmente nos estudos empíricos que postulam uma relação linear entre as variáveis, mas a magnitude do efeito é pequena, incompatível com as experiências de alta inflação e desempenho econômico medíocre.

O estudo de Sarel (1996) investigou a existência de uma relação não-linear entre as duas variáveis, e os resultados apontam um efeito positivo (mas insignificante em geral) para valores inferiores a uma taxa de $8 \%$ ao ano, e fortemente negativo a partir deste valor. No entanto, o estudo de Sarel só contém dados até 1990, sendo provável que a relação tenha mudado em virtude da maior ênfase no combate à inflação. Há de fato uma redução perceptível nas taxas médias de inflação mundial a partir dos anos 90 .

A metodologia de Sarel foi replicada pelos autores do presente artigo para 55 países com dados até 2004, com o intuito de reavaliar a relação entre inflação e crescimento, e discutir as suas diferenças entre países desenvolvidos e em desenvolvimento. A estimação segue os estudos tradicionais dos determinantes do crescimento, onde a variável dependente é a taxa de crescimento do PIB per capita sendo explicada pela renda per capita inicial (para testar a convergência no crescimento), pela taxa de crescimento da população, pelo percentual de investimento no PIB, o percentual dos gastos do governo e pela variação dos termos de troca ${ }^{4}$, além da taxa de inflação. Seguindo a recomendação de Sarel (1996), dado que as observações para a taxa de inflação têm uma distribuição bastante assimétrica à direita, isto é,

\footnotetext{
${ }^{2}$ Este ponto foi explorado pioneiramente por Tobin (1972).

${ }^{3}$ Dependendo da estrutura dos impostos, este efeito pode ser bastante negativo. Ver Feldstein (1996).

4 A introdução da variação dos termos de troca é feita para isolar a correlação negativa entre crescimento e inflação no caso dos choques negativos sobre os termos de troca.
} 
estão concentradas no espectro de menor valor, trabalhamos com uma transformação da taxa de inflação, o Ln da inflação. $\mathrm{O}$ valor da quebra ${ }^{5}$ é escolhido de forma a maximizar o $\mathrm{R}^{2}$ da estimação econométrica.

Os resultados apresentados na tabela 1 abaixo, apontam para uma queda da taxa de inflação a partir da qual o crescimento é prejudicado: dos $8 \%$ obtidos no estudo de Sarel o valor reduz-se a apenas 2,5\% para o conjunto dos países. Este valor está de acordo com a inflação média nos países desenvolvidos e poderia indicar que uma meta de inflação como a do Brasil, de 4,5\%, é contraproducente para o crescimento. No entanto, ao considerarmos apenas os países em desenvolvimento, a taxa de quebra na relação eleva-se para 5,1\% contrariando a premissa anterior, ao passo que se considerássemos apenas os paises desenvolvidos o valor cairia para apenas 2,1\%. Os resultados são estatisticamente significativos e apontam uma diferença de cerca de 3 p.p. entre a inflação "ótima” para países desenvolvidos e em desenvolvimento.

\begin{tabular}{llll}
\hline Grupos de Países & Todos & $\begin{array}{l}\text { Países } \\
\text { Desenvolvidos }\end{array}$ & $\begin{array}{l}\text { Países em } \\
\text { Desenvolvimento }\end{array}$ \\
\hline $\mathrm{R}^{2}$ & 0,5978 & 0,6834 & 0,5728 \\
Observações & 336 & 96 & 240 \\
Valor da Quebra & $2,5 \%$ & $2,1 \%$ & $5,1 \%$ \\
\hline Variável dependente: Crescimento do PIB per capita & & \\
\hline Constante & 0,3336302 & 0,3561859 & 0,3349428 \\
LN da inflação & 0,005622 & 0,0080728 & 0,0018363 \\
Quebra & $-0,0142325$ & $-0,0197364$ & $-0,0112985$ \\
Taxa de crescimento da população & $-0,5499639$ & 0,364807 & $-0,7149263$ \\
Investimento/PIB & 0,0185557 & 0,0358053 & 0,0167706 \\
Gastos do governo/PIB & 0,001653 & 0,0026263 & $-0,0004252$ \\
Variação nos termos de troca & 0,1010945 & 0,1617251 & 0,0932082 \\
LN da renda per capita inicial & $-0,0381043$ & $-0,0417373$ & $-0,0387591$ \\
Efeito da inflação após a quebra & $-0,0086104$ & $-0,0116635$ & $-0,0094622$ \\
Teste de Breush-Pagan para a & chi2(1) $=33$ & chi2 $2(1)=9,60$ & chi2 $2(1)=24,00$ \\
presença de efeitos aleatórios & Prob $>$ chi2 $=$ & Prob $>$ chi2 $=$ & Prob $>$ chi2 \\
& 0,0000 & 0,0019 & $=0,0000$ \\
\hline Fo & & & \\
\hline
\end{tabular}

Fonte: elaborado pelos autores a partir de dados da pesquisa.

Nível de Significância: * $\mathrm{p}<0,10 \quad * * \mathrm{p}<0,05 * * * \mathrm{p}<0,01$

5 A quebra é definida através de uma variável dummy que assume valor zero para $\left(\pi<\pi^{*}\right)$ e valor (Lncpi $\operatorname{Ln}\left(\pi^{*}\right)$ para $\left(\pi \geq \pi^{*}\right)$. 
Os resultados da tabela 2 apontam não só para as diferença entre as quebras, mas que o efeito negativo da inflação sobre o crescimento após a quebra ${ }^{6}$ é mais oneroso no caso dos países desenvolvidos. No entanto, quando o valor da inflação está abaixo da meta, o impacto só é positivo sobre o crescimento para os países desenvolvidos ou para o conjunto da amostra. O impacto do dobro de inflação após a quebra sobre a taxa de crescimento do PIB per capita é de cerca de $-0,67 \%$ para os países em desenvolvimento, contra $-0,84 \%$ no caso dos desenvolvidos ${ }^{7}$. Embora a diferença não seja tão grande (e ambos os coeficiente sejam significativos a 1\%), se considerarmos os limites inferiores e superiores do intervalo estimado, o impacto no caso dos desenvolvidos compreende-se entre (-1,5\% e $0,21 \%)$, enquanto para os países em desenvolvimento os limites dos intervalos são (-1\% e 0,35\%). As outras variáveis na regressão têm o efeito esperado de acordo com os estudos sobre os determinantes do crescimento.

A diferença na meta ótima de inflação entre países desenvolvidos e desenvolvimento pode ser resultado de uma série de fatores históricos, mas um argumento teórico de comércio internacional é normalmente utilizado para explicar esta diferença. Trata-se de uma conseqüência do efeito Balassa-Samuelson. O efeito deriva-se da diferença de produtividade entre os setores de bens comercializáveis e não-comercializáveis. Dado que os setores dos bens comercializáveis são expostos à concorrência externa, a sua produtividade é normalmente mais elevada e os salários reais mais altos, mas como a determinação dos preços no setor de comercializáveis é externa, os preços neste setor sobem menos do que nos setores de bens não comercializáveis. No entanto, os salários são determinados internamente devido à pequena mobilidade da mão-de-obra, fazendo com que a concorrência entre os setores promova uma equalização dos salários, inflando os preços dos bens não-comercializáveis devido à sua menor produtividade. A conseqüência deste efeito sobre a inflação é que a convergência de renda dos países em desenvolvimento em direção aos desenvolvidos, tenderá a elevar o preço relativo dos bens não-comercializáveis dentro dos países, pressionando os indicadores de inflação ${ }^{8}$.

A conclusão a que podemos chegar é que a meta para a taxa de inflação brasileira não precisa ser mudada nos próximos anos, pois ela se encontra em um patamar inferior à média

\footnotetext{
${ }^{6}$ Repare que o efeito líquido da inflação sobre o crescimento após à quebra é a soma dos coeficientes para o $L n$ da inflação e a variável Quebra.

${ }^{7}$ A comparação aqui inclui as dummies para os países.

${ }^{8}$ Este ponto é explorado por Amato e Gerlach (2002).
} 
da quebra para os países em desenvolvimento, e que não traz, portanto, prejuízos evidentes ao crescimento econômico. As atenções das autoridades monetárias devem ser voltadas a outros assuntos de urgência que impedem o crescimento da economia brasileira.

\section{Referências bibliográficas}

AMATO, J. D; GERLACH, S. (2002). "Inflation targeting in emerging market and transition economies: Lessons after a decade" In: European Economic Review, Vol. 46, p. 781-790.

FELDSTEIN, M. (1996). "The Costs and Benefits of going from Low Inflation to Price Stability" In: National Bureau of Economic Research. Working Papers, $n^{\circ} 5469$, February.

GHOSH, A.; PHILLIPS, S. (1998). "Warning: Inflation Maybe Harmful to Your Growth" In: IMF Staff Papers, Vol. 45, n 4, p.672-710.

GROSHEN, E. L.; SCHWEITZER, M. E. (1997). “Identifying Inflation's Grease and Sand Effects in the Labor Market" In: National Bureau of Economic Research. Working Papers, $\mathrm{n}^{\circ} 6061$.

HESTON, A.; SUMMERS, R.; ATEN, B. (2006). Penn World Table Version 6.2. In: Center for International Comparisons at the University of Pennsylvania (CICUP). September.

SAREL, M. (1996). "Nonlinear Effects of Inflation on Economic Growth" In: IMF Staff Papers, Vol. 43, no 1, p. 199-215.

TOBIN, J. (1972). "Inflation and Unemployment" In: The American Economic Review, Vol. 62, no $1 / 2$, p. 1-18.

WORLD BANK (2006) “World Development Indicators" In: WDI On-line, World Bank, Washington. 
